\title{
Formulation and Evaluation of Biphasic Gastro Floating Tablets of Nateglinide and Atenolol
}

\author{
Subham Gupta $^{1}$ (D), Ranjit Prasad Swain ${ }^{2, *(D)}$, Bharat Bhusan Subudhi ${ }^{3}$ (D), Abhishek Bhattacharjee ${ }^{4}$ (i) \\ 1 Department of Pharmaceutical Technology, Maharajah's College of Pharmacy, Vizianagaram-535002, Andhra Pradesh, \\ India \\ 2 Department of Pharmaceutics, School of Pharmaceutical Sciences, Siksha O Anusandhan (Deemed to be University), \\ Bhubaneswar, Odisha, India \\ 3 Drug Development and Analysis Laboratory, School of Pharmaceutical Sciences, Siksha O Anusandhan (Deemed to be \\ University), Bhubaneswar, Odisha, India \\ 4 Department of Pharmaceutical Sciences, Assam University, Silchar-788011, Assam, India \\ * Correspondence: ranjit.prasad797@gmail.com;
}

Scopus Author ID 55904990800

Received: 10.10.2020; Revised: 10.11.2020; Accepted: 12.11.2020; Published: 15.11.2020

\begin{abstract}
The aim was to design, formulate, and evaluate bilayer gastro floating tablets of an antidiabetic agent, nateglinide (immediate-release layer), and antihypertensive agent, atenolol (sustained-release layer). The solubility of model drug nateglinide was enhanced by using cremophor RH 40 and characterized by FTIR, DSC, XRD, SEM, and in vitro dissolution. It was found that selected ingredients were compatible, and crystalline nateglinide transits to an amorphous state. The gastrobilayer tablets were directly compressed using the optimized nateglinide (solid dispersion equivalent to $60 \mathrm{mg}$ of nateglinide) immediate-release layer (IRL2) containing different percentage of F-Melt type C and crospovidone and atenolol $(50 \mathrm{mg}$ ) sustained-release layer (SRL6) using different percentage of HPMC K15, sodium bicarbonate, and MCC. Developed tablets were evaluated and found within the acceptance range as per the guidelines. The release of nateglinide and atenolol from an optimized bilayer tablet (BLT3) was $100 \%$ within $60 \mathrm{~min}$ and $12 \mathrm{~h}$, respectively. The floating lag time and total floating time were $2 \mathrm{~min}$ and $12 \mathrm{~h}$, respectively. The atenolol sustained-release followed the diffusion mechanism. The combination of nateglinide and atenolol was successfully showed a biphasic release pattern. This formulation may strengthen the fixed-dose combination therapy for diabetes and hypertension at a low cost.
\end{abstract}

Keywords: Nateglinide; atenolol; biphasic; floating lag time; total floating time.

(C) 2020 by the authors. This article is an open-access article distributed under the terms and conditions of the Creative Commons Attribution (CC BY) license (https://creativecommons.org/licenses/by/4.0/).

\section{Introduction}

High patient compliance, stability, and flexibility with formulation make the oral drug delivery most satisfactory, and it occupies $32 \%$ of the market share [1]. Frequent administration showed fluctuation of the drug plasma concentration and toxicity [2]. Sustainedrelease was a delivery system to solve these problems and deliver the drugs in an extended period of time. Drugs with a narrow absorption window, alteration in emptying time of stomach, stability issues in the intestine, and drugs transported via active transport mechanism are the difficulty of this system [3]. Gastro retentive drug delivery system (GDDS) has been developed to surmount these problems. This system helps to remain the drug for a prolonged period of time in the gastric cavity. This improves solubility, bioavailability, and reduces the wastage of the drug in the gut [4]. In this system, the drug was delivered locally to the stomach 
as well as the proximal small intestine [5]. The floating drug delivery system is one of the most favorable among the gastroretentive dosage forms. The motility of GIT does not affect this system [6]. The matrix bilayer floating tablet is a novel system for the delivery of the therapeutic agents. Simultaneous and desired release profile, decrease the frequency of drug administration with better patience compliance, synergistic effect leading to increase the efficacy and deliver two chemically incompatible drugs into a system are the benefits of this system [7].

In the $21^{\text {st }}$ century, diabetes and cardiovascular diseases are common in society leads to global health emergencies. Globally approximately 463 million adults (20-79 years, 1 in 11 adults) have diabetes in 2019 [8, 9]. If these trends continue, by 2030, 578 million adults have diabetes (IDF, 2019) [9]. Surprisingly, $10 \%$ of the global health budgets are spent on diabetes. According to WHO, globally estimated 1.13 billion people have hypertension [10]. The coexistence/co-occurrence of hypertension and diabetes is very high all over the world [11-13]. It escalates the risks of strokes, retinopathy, nephropathy. The commonness of hypertension with diabetes is up to threefold more than without disease in age-matched subjects $[11,12]$. These patients spent 1.43 times more than diabetes without hypertension in India. It is a great challenge as the response to treatment is poor and to normalize the blood pressure in diabetes condition. The prevalence of diabetes and hypertension among young adults and old age across all geographical areas and socio-demographic groups in India was higher [11]. Therefore, diabetes and hypertension often co-exist and may require concomitant drug treatment $[14,15]$.

Nateglinide (BCS Class II) is an anti-diabetes agent (type 2 diabetes) and has excellent safety and tolerability profile. It shows variable bioavailability due to poor water solubility [16]. To achieve better therapeutic efficacy, nateglinide was selected to prepare an immediate drug release layer through enhancement of solubility. Atenolol ( $\beta$-blockers) is a widely recommended first-line antihypertensive drug [17]. It has an absorption window in the upper GIT, whereas the poor absorption in the lower GIT. This variable absorption leads to lower bioavailability (50\%) with a half-life of 6-8 $\mathrm{h}$ [18]. This can be addressed by increasing gastric residence time of atenolol. Increasing the gastric residence time may promote higher absorption leading to enhanced bioavailability. Hence including atenolol in the sustained release layer may improve gastric retention and its bioavailability.

Formulating biphasic systems with immediate and sustained-release layer has been a successful strategy for developing new drug combinations. Similar formulation with metformin in the sustained-release layer and pioglitazone in the immediate-release layer has been reported to address poor absorption of metformin while reducing the risk of atherosclerosis due to pioglitazone [19]. In our earlier research, we have used a similar strategy with the immediaterelease of ezetimibe [6] and simvastatin [20] and sustained-release of atenolol as bilayer gastro floating tablets. Thus the strategy for the immediate-release of nateglinide and sustainedrelease of atenolol may enhance the potential for enhancement in the bioavailability of these drugs. Keeping this in consideration, the investigation was carried out to develop and optimize bilayer gastro-floating tablet of nateglinide and atenolol for potential application as a fixeddose combination against comorbidity of diabetes and hypertension.

\section{Materials and Methods}

Nateglinide was collected from Aurobindo Pharma Ltd., India, as a gift sample. Cremophor RH 40 was supplied by BASF, Germany. Atenolol, crospovidone, aerosol were obtained from Yarrow Chem Products (Mumbai, India). F Melt type C was received from Fuji 
Chemical Industries Co., Ltd, Japan, as a gift sample. Hydroxypropyl methylcellulose (HPMC) and compritol 888 ATO were received by Piramal Health Care (Bengaluru, India) and Gattefosse, India, respectively as gift sample. Microcrystalline cellulose was obtained from Otto Chemica Biochemica Reagents, India.

\subsection{Preparation of the immediate-release layer.}

The feasible industrial technique, solid dispersion (SD) was chosen to enhance the solubility of model anti-diabetes agent nateglinide with cremophor RH 40 and aerosol. SDs at various weight ratios were formulated by the suitable solvent evaporation method. Different weight ratios of 1:0.25, 1:0.5, 1:0.75, 1:1 drug, and carrier (cremophor RH 40) were weighed individually and were dissolved in $10 \mathrm{~mL}$ ethanol to get a clear solution. The polymer solution was added to the drug solution with continuous stirring. Ethanol was completely removed by continuous heating on a heating plate at $40-50{ }^{\circ} \mathrm{C}$, which was carried out until a semisolid mass was obtained. The aerosil $(0.02 \% \mathrm{w} / \mathrm{w})$ was added to make solid in nature and free-flowing. The powder was kept in a desiccator for further study [21]. The formulations were named F1F8.

\subsection{Percentage yield.}

The practical yield was calculated in an appropriate method that signifies the efficiency of any method [6].

\subsection{Drug content test.}

The percentage of drug content in SD's, was estimated by dissolving the SDs equivalent to $10 \mathrm{mg}$ of nateglinide in $5 \mathrm{~mL}$ of ethanol. Each of these solutions was further diluted with $0.01 \mathrm{~N} \mathrm{HCl}$ buffer, and nateglinide was analyzed at a wavelength of $245 \mathrm{~nm}$ by U.V. Visible spectrophotometer (Model: cary 60, Agilent, USA) [6, 18].

\subsection{Fourier transforms in infrared spectroscopy (FTIR).}

The prepared formulations, pure drugs, polymers/excipients were scanned at a resolution of $2 \mathrm{~cm}^{-1}$, from 4000 to $400 \mathrm{~cm}^{-1}$ using FTIR (Cary 60, Agilent Technologies, USA). The FTIR spectra were obtained for the characterization of functional groups.

\subsection{Differential scanning calorimetry (DSC).}

DSC (Pyris Diamond, Singapore) thermograms of nateglinide, cremophor RH 40, and SDs were recorded. Operating conditions: heating rate $\left(10^{\circ} / \mathrm{min}\right)$, temperature $30-280{ }^{\circ} \mathrm{C}$, alumina powder as reference.

2.6. $X$-ray diffraction analysis $(X R D)$.

XRD diffraction pattern of nateglinide, cremophor RH 40, and SDs were recorded using ULTIMA III, Japan (Cu target slit $10 \mathrm{~mm}$ ). 


\subsection{Scanning electron microscopy (SEM).}

Nateglinide and SDs were subjected to SEM analysis using JSM6360, Jeol SEM (UK), to investigate morphological characteristics. Operating conditions: probe current $45 \mathrm{nA}$, accelerating voltage $20 \mathrm{kV}$, counting time $60 \mathrm{sec}$.

\subsection{In vitro dissolution studies.}

The dissolution was performed using USP II (paddle) dissolution apparatus (Electrolab, Mumbai, Model: TDT-08 L) in triplicate. The operation conditions of dissolution: temperature $37 \pm 0.5^{\circ} \mathrm{C}$ and paddle rotation speed $50 \mathrm{rpm}$. Nateglinide and developed SDs equivalent to 60 mg nateglinide were individually placed in $1000 \mathrm{~mL}$ of $0.01 \mathrm{~N} \mathrm{HCl}$ with $0.5 \% \mathrm{w} / \mathrm{v}$ sodium lauryl sulfate (SLS). At predetermined time intervals 5, 10, 15, 30, 45, and $60 \mathrm{~min}, 5 \mathrm{~mL}$ of aliquots were withdrawn. The equal quantity was replaced with a preheated medium after each sampling. The aliquots were filtered using a $0.45 \mu \mathrm{m}$ syringe filter and analyzed at a wavelength of $245 \mathrm{~nm}$ using a UV-Visible spectrophotometer (Agilent, Cary 60).

\subsection{Compression of immediate-release and sustained-release layer tablets.}

Based on physicochemical characterizations, SDs containing nateglinide and cremophor RH 40 in the weight ratio of 1:0.25 and $0.02 \% \mathrm{w} / \mathrm{w}$ aerosol (F5) (of drug equivalent to $60 \mathrm{mg}$ of nateglinide) was selected to formulate into immediate-release tablets. All the ingredients of the immediate-release layer (IRL1-IRL3) (Table 1) and sustained- release layer (SRL1-SRL12) (Table 2) were weighed separately and passed through sieve 44\#. Two layers of ingredients were taken in a mortar separately and mixed using a pestle. Magnesium stearate was added before punching tablets by the direct compression method.

Table 1. Formulation of immediate-release layer tablets by direct compression method.

\begin{tabular}{l|c|c|c|c|c}
$\begin{array}{l}\text { Formulation } \\
\text { code }\end{array}$ & $\begin{array}{c}\text { SD } \\
\text { equivalent 60 } \\
\text { mg of nateglinide (F5) }\end{array}$ & $\begin{array}{c}\text { F Melt } \\
\text { type-C } \\
(\mathbf{m g})\end{array}$ & $\begin{array}{c}\text { Crospovidone } \\
(\mathbf{m g})\end{array}$ & $\begin{array}{c}\text { Magnesium } \\
\text { stearate (mg) }\end{array}$ & $\begin{array}{c}\text { Total } \\
(\mathbf{m g})\end{array}$ \\
\hline IRL1 & 75 & 74 & - & 1 & 150 \\
\hline IRL2 & 75 & 72 & 3 & 1 & 150 \\
\hline IRL3 & 75 & 68 & 6 & 1 & 150
\end{tabular}

Each batch contains 50 tablets

Table 2. Formulation of sustained-release layer by direct compression method.

\begin{tabular}{|c|c|c|c|c|c|c|c|c|}
\hline $\begin{array}{l}\text { Formulation } \\
\text { code }\end{array}$ & $\begin{array}{l}\text { Drug } \\
\text { (mg) }\end{array}$ & $\begin{array}{l}\text { HPMC } \\
\text { K100 } \\
(\mathrm{mg})\end{array}$ & $\begin{array}{l}\text { HPMC } \\
\text { K15 } \\
(\mathrm{mg})\end{array}$ & $\begin{array}{l}\text { Eudragit } \\
\text { RS } 100 \text { (mg) }\end{array}$ & $\begin{array}{l}\text { Compritol } \\
888 \text { ATO (mg) }\end{array}$ & $\begin{array}{l}\text { MCC } \\
(\mathbf{m g})\end{array}$ & $\begin{array}{l}\text { Magnesium } \\
\text { Stearate } \\
(\mathrm{mg})\end{array}$ & $\begin{array}{l}\text { Total } \\
(\mathbf{m g})\end{array}$ \\
\hline SRL1 & 50 & 50 & - & - & - & 192 & 8 & 300 \\
\hline SRL2 & 50 & 100 & - & - & - & 142 & 8 & 300 \\
\hline SRL3 & 50 & 150 & - & - & - & 92 & 8 & 300 \\
\hline SRL4 & 50 & - & 50 & - & - & 192 & 8 & 300 \\
\hline SRL5 & 50 & - & 100 & - & - & 142 & 8 & 300 \\
\hline SRL6 & 50 & - & 150 & - & - & 92 & 8 & 300 \\
\hline SRL7 & 50 & - & - & 50 & - & 192 & 8 & 300 \\
\hline SRL8 & 50 & - & - & 100 & - & 142 & 8 & 300 \\
\hline SRL9 & 50 & - & - & 150 & - & 92 & 8 & 300 \\
\hline SRL10 & 50 & - & - & - & 50 & 192 & 8 & 300 \\
\hline SRL11 & 50 & - & - & - & 100 & 142 & 8 & 300 \\
\hline SRL12 & 50 & - & - & - & 150 & 92 & 8 & 300 \\
\hline
\end{tabular}

Each batch contains 50 tablets 


\subsection{Preparation of gastro-bilayer floating tablets (GBFTs).}

Based on the dissolution profiles and solid-state characterizations, formulation IRL2 (immediate-release) and SRL6 (sustained-release) were taken for the preparation of GBFTs. A varying concentration of sodium bicarbonate was added in the sustained-release layer (Table 3). GBFTs were fabricated by feeding the sustained-release followed by immediate-release layer power to the die cavity. Tablets were compressed using a $12 \mathrm{~mm}$ flat punch with an acceptable hardness of $5.5-6.5 \mathrm{~kg} / \mathrm{cm}^{2}$.

Table 3. Compression of gastro-bilayer floating tablets.

\begin{tabular}{l|l|l|l} 
Ingredients (mg) & BLT1 & BLT2 & BLT3 \\
\hline $\begin{array}{l}\text { Immediate-release layer } \\
\text { SD equivalent to 60 mg of nateglinide }\end{array}$ & 75 & 75 & 75 \\
\hline F-Melt type C & 72 & 72 & 72 \\
\hline Crospovidone & 3 & 3 & 3 \\
\hline $\begin{array}{l}\text { Sustained-release layer } \\
\text { Atenolol }\end{array}$ & 50 & 50 & \\
\hline HPMC K15 & 150 & 150 & 150 \\
\hline Sodium bicarbonate & 12.5 & 25 & 50 \\
\hline MCC & 129.5 & 117 & 92 \\
\hline Magnesium stearate & 8 & 8 & 8 \\
\hline Total & 500 & 500 & 500
\end{tabular}

\subsection{Post compression parameters of GBFTs.}

The thickness of the ten randomly selected tablets from each batch was determined with the Vernier caliper scale (Model: 530-312, Japan).

\subsection{Weight variation.}

Randomly twenty tablets were selected from each batch and calculated the percentage deviation of individual tablet weight from the average weight of tablets.

\subsection{Crushing strength.}

Crushing strength was determined using Monsanto type hardness tester by selecting randomly six tablets from each batch.

\subsection{Friability.}

As the weight of the formulation was $500 \mathrm{mg}, 6.5 \mathrm{~g}$ of the tablet was used for the friability test as per IP (2010). The tablets were put into the Roche friabilator apparatus (Model: 40 FT A01). With a rotation speed of $25 \mathrm{rpm}$, it was rotated for 4 min while allowing the tablets to fall from a height of 6 inches in each turn. Following this, the tablets were weighed again, and the loss in weight was expressed in percentage as a parameter of friability following the official method of IP 2010.

\subsection{Drug content.}

The average drug content was analyzed after verifying the UV-Visible spectrophotometric method for the simultaneous estimation of nateglinide and atenolol from bulk (Fig. S1 and Table S1-S6). Briefly, 20 tablets were crushed, and powder equivalent to 50 $\mathrm{mg}$ of drug combination was transferred to a $50 \mathrm{~mL}$ volumetric flask and dissolved in $0.1 \mathrm{M}$ 
$\mathrm{HCl}$. This was sonicated to ensure a homogeneous solution. This was further filtered $1 \mathrm{~mL}$ of the filtrate was used for estimation of drug content at a wavelength of $232.7 \mathrm{~nm}$.

\subsection{In vitro floating ability.}

The floating or buoyancy ability to float tablets was determined following established protocols [22]. Briefly, the tablet was placed in a beaker containing $250 \mathrm{~mL}$ of $0.1 \mathrm{M} \mathrm{HCl}$. Floating lag time (FLT) was noted as the time taken by the tablet to appear on the surface of the medium. Similarly, the time to constantly float on the medium was considered as the total float time (TFT).

\subsection{Dissolution studies of GBFTs.}

The dissolution study was carried out by operating the USP type II apparatus (paddle method) at $50 \mathrm{rpm}$ and $37 \pm 0.5^{\circ} \mathrm{C}$ temperature. The developed GBFT was placed in $900 \mathrm{~mL}$ of $0.1 \mathrm{~N} \mathrm{HCl}(\mathrm{pH} 1.2$ simulating gastric $\mathrm{pH})$ dissolution medium. Aliquots of $5 \mathrm{~mL}$ from each were withdrawn at specified time intervals of $5,10,15 \mathrm{~min}, 0.5,0.75,1,2,3,4,5,6,7,8,9$, 10,11 , and $12 \mathrm{~h}$. Equal volume was replaced with fresh preheated medium after each sampling. The aliquots were filtered using $0.45 \mu \mathrm{m}$ Millipore syringe filters. The filtrates were analyzed at a wavelength of $232.7 \mathrm{~nm}$ for the estimation of nateglinide and atenolol simultaneously.

\subsection{Release kinetics.}

In vitro, drug release data were subjected to mathematical models like zero order, first order, Higuchi, Hixson Crowell, Korsmeyer, and Peppas in order to investigate the release pattern of formulated batches [23, 24].

\section{Results and Discussion}

Nateglinide (BCS Class II) is practically insoluble in water $(8.8 \mathrm{mg} / \mathrm{L})$ [25]. In order to meet the aim of the study, an attempt was made to improve the solubility of nateglinide. There are eight different formulations (F1-F8) that were prepared with cremophor RH 40 and with and without aerosol $(0.02 \% \mathrm{w} / \mathrm{v})$ by solvent evaporation technique in a weight ratio of 1:0.25, $1: 0.5,1: 0.75,1: 1$. The formulations were subjected to physicochemical characterization like FTIR, DSC, XRD, SEM, and in vitro dissolution studies.

\subsection{FTIR.}

The FTIR study provides evidence of the chemical/physical interaction and the shifting of the bonds. The FTIR spectrum of the nateglinide, cremophor RH 40, and its developed SDs are shown in Figure 1. Nateglinide has a $\mathrm{C}=\mathrm{O}$ group, which may participate in intermolecular interactions. Solutol HS 15 and cremophor RH 40 has functional groups which could favor the interaction with nateglinide by hydrogen bonding. The characteristic peaks of nateglinide [26] were observed at $3307.92 \mathrm{~cm}^{-1}$ for $\mathrm{N}-\mathrm{H}$ stretching and $3068.75 \mathrm{~cm}^{-1}$ for aromatic $\mathrm{C}-\mathrm{H}$ stretching. C-H symmetric and asymmetric stretching were observed at 2964.59 and 2918.30 $\mathrm{cm}^{-1}$, respectively (Figure $1 \mathrm{~A}$ ). $\mathrm{C}=\mathrm{O}$ stretching was assigned to $1687.71 \mathrm{~cm}^{-1}$. SDs showed a slight shifting of the peaks corresponding to $\mathrm{N}-\mathrm{H}$ and carbonyl stretching groups (Figure 1D). This may occur due to hydrogen bond formations (non-covalent interactions) with polymeric groups, which might contribute to the enhancement of solubility of nateglinide in the SDs. 
There was no chemical interaction between the nateglinide and cremophor RH 40. The optimized formulation showed characteristic peaks of the drugs and excipients (Figure 1E) that indicate the compatibility between them.

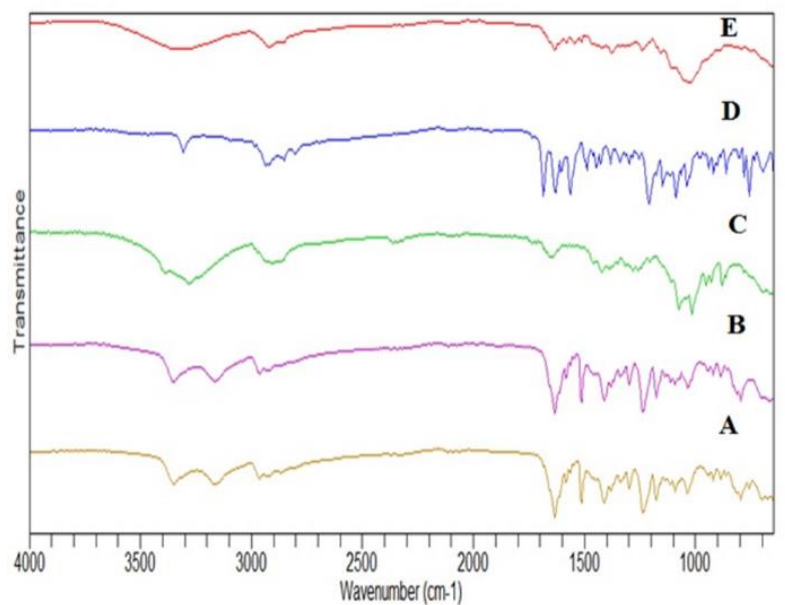

Figure 1. FTIR absorption spectra of A) nateglinide, B) atenolol, C) cremophor RH 40, D) nateglinide SD (F5), and E) optimized bilayer tablet (BLT3).

\subsection{DSC.}

The DSC thermographs of nateglinide, cremophor RH 40, and SDs are depicted in Figure 2. Nateglinide recorded a melting point at $136.67^{\circ} \mathrm{C}(\Delta \mathrm{H}=89.83 \mathrm{~J} / \mathrm{g})$ suggesting its crystallinity (Figure 2A) [23, 26]. The endotherm of cremophor RH 40 displayed a melting point at around $32.2{ }^{\circ} \mathrm{C}$ (Figure 2B). The nateglinide melting peak disappeared in SD when prepared with cremophor RH 40 (Figure 2C). This indicates the amorphous state of the drug and that the amount of cremophor RH 40 used was sufficient to solubilize nateglinide.

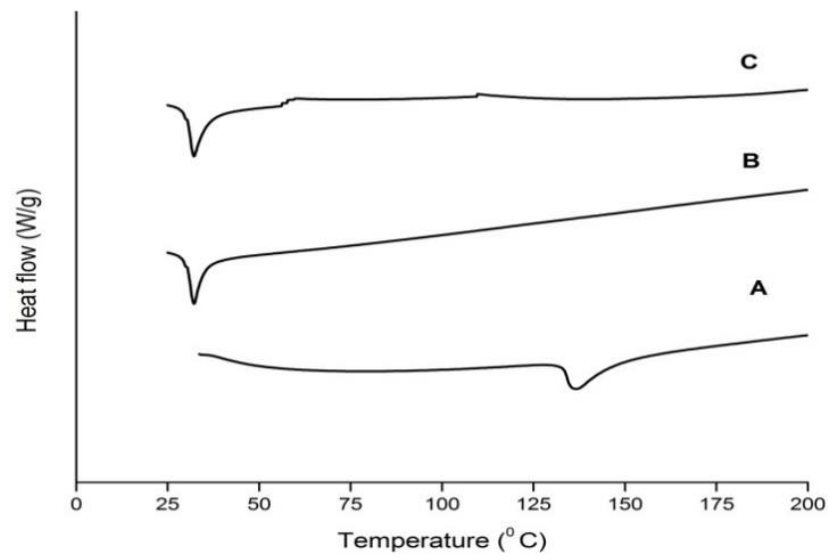

Figure 2. DSC thermograms of A) nateglinide, B) cremophor RH 40 and C) nateglinide SD (F5).

\subsection{XRD.}

The peak heights of nateglinide, cremophor RH 40, and their SDs are exhibited in Figure 3. Pure drug nateglinide exhibited sharpener and intense peak at diffraction angles $\left(2 \theta^{\circ}\right)$ equivalent to $7.44^{\circ}, 9.94^{\circ}, 12.28^{\circ}, 12.88^{\circ}, 13.10^{\circ}, 13.64^{\circ}, 14.48^{\circ}, 16.56^{\circ}, 17.42^{\circ}, 18.5^{\circ}, 20.22^{\circ}$, $20.42^{\circ}, 21.4^{\circ}, 22.44^{\circ}, 22.86^{\circ}, 23.92^{\circ}, 30.87^{\circ}$. Maggi et al. [25] observed the same pattern of the nateglinide indicates the strong crystal habit of the pure drug. Cremophor RH 40 (Figure 3B) exhibited no characteristics peaks indicating their amorphous nature. The XRD diffractogram of nateglinide in cremophor RH 40 showed the disappearance of drug peaks (Figure 3C). This 
suggests conversion to an amorphous state. The amount of cremophor RH 40 was sufficient to solubilize the drug in solvent evaporation techniques. This is in agreement with the DSC data.

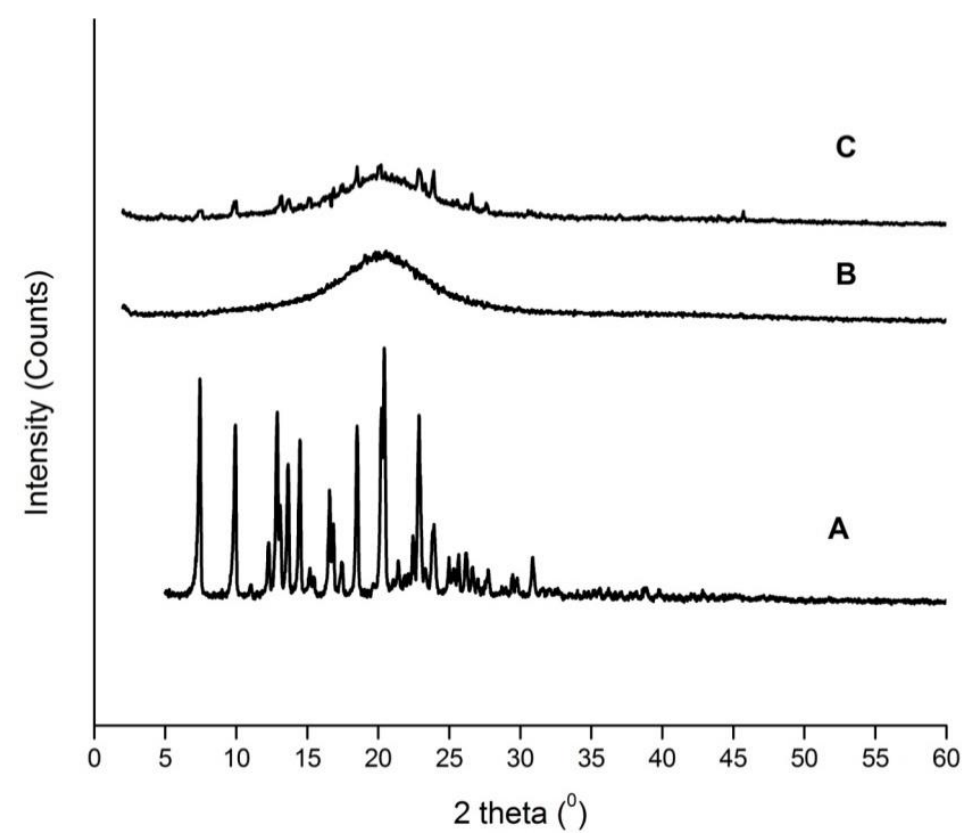

Figure 3. XRD pattern of A) nateglinide, B) cremophor RH 40 and C) nateglinide SD (F5).

\subsection{SEM.}

SEM photomicrographs of nateglinide and its selected SD formulations are shown in Figure 4. Pure drug nateglinide demonstrated rod-shaped crystallites with various sizes (Figure 4A). This is in agreement with the DSC and XRD data. Photographs of SD (Figure 4B) indicated a loss of crystallinity, which might be the reason for the faster dissolution of the nateglinide.
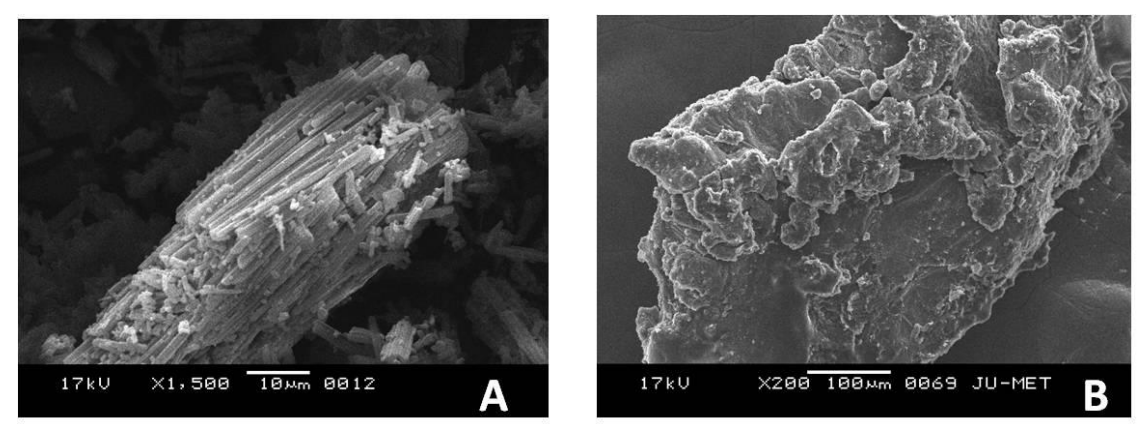

Figure 4. SEM image of A) nateglinide and B) nateglinide SD.

\subsection{In-vitro dissolution studies.}

The dissolution profiles of pure drug nateglinide and prepared SD are shown in Figure 5. A small amount of SLS in the dissolution medium was more similar to physiologically bile salt, which was a natural surfactant useful for the dissolution of BCS class II drugs [28]. So, SLS will satisfy their needs. Therefore the dissolution was performed in $0.1 \mathrm{~N} \mathrm{HCl}$ with a 0.5 $\%$ SLS solution. The pure drug nateglinide showed an incomplete drug release $(23.01 \pm 1.99)$ within $60 \mathrm{~min}$ of dissolution. Incorporation of carriers showed enhancement of solubility. There was a 7.57 fold enhancement of dissolution observed for SD as compared with pure drug. The quick enhancement $(99.92 \pm 1.21)$ of dissolution at 30 min may be due to the interaction 
of surfactant carrier cremophor RH 40 and drug. In 60 min of dissolution, SD showed complete drug release $(99.92 \pm 1.21)$. This was approximately 4.34 fold more than pure drug. This was supported by DSC, XRD, and SEM analysis. This formulation F5 was further used for the preparation of the immediate-release layer.

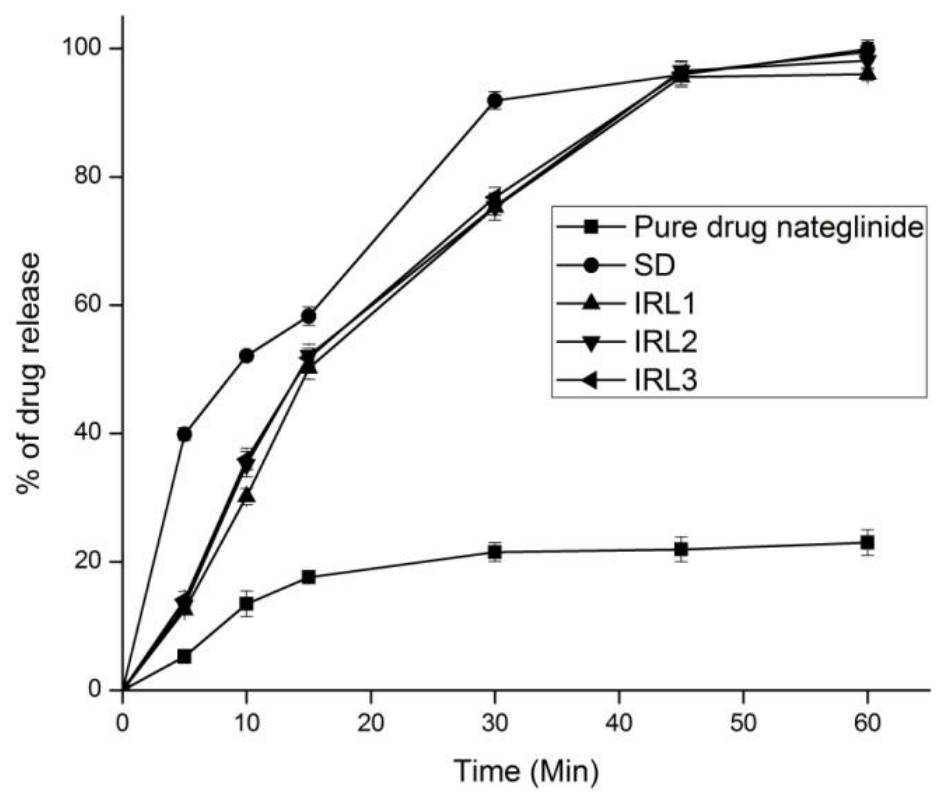

Figure 5. In-vitro release profile of solubility enhancement of nateglinide and in-vitro release profile of immediate-release layer.

3.6. Compression of an immediate-release layer and a sustained-release layer.

$\mathrm{SD}$ equivalent to $60 \mathrm{mg}$ of nateglinide was taken and formulated into immediaterelease tablet by $\mathrm{F}$ Melt type $\mathrm{C}$ and varying the concentrations of super disintegrant crospovidone (Table 1). Sustained-release tablets were formulated by varying the concentration of release retardants (HPMC K100, HPMC K15, Eudragit RS 100, and Compritol 888 ATO) (Table 2). The powder blends were compressed individually by using a direct compression method. In-vitro dissolution studies were performed to optimize the formulations for the development of bilayer tablets.

\subsection{In vitro dissolution.}

The in-vitro release profile of immediate-release formulations (IRL1-IRL3) is shown in Figure 5. The formulations IRL1 and IRL2 showed $96 \%$ and $98 \%$ drug release within $1 \mathrm{~h}$, which was less than the IRL3 formulation (99.5\%). This shows a nearly 5 fold increase in dissolution efficiency when compared to a pure drug over a period of $1 \mathrm{~h}$. This may be due to the crospovidone in the immediate-release layer that swells by absorbing the liquid medium by wicking and help to liberate nateglinide with fine dispersion. Therefore, the IRL3 formulation was selected as an immediate-release in the preparation of GBFTs.

The release profiles of atenolol formulations (SRL1-SRL12) are illustrated in Figure 6. The formulations with HPMC K15 (SRL4, SRL5, SRL6) showed $100 \%$ of drug release within 9-12 h whereas HPMC K100 (SRL1, SRL2, SRL3), eudragit RS 100 (SRL7, SRL8, SRL9) and compritol 888 ATO (SRL10, SRL11, SRL12) showed $100 \%$ drug release in 5-7h respectively. This showed that HPMC K100, eudragit RS 100, and compritol 888 ATO polymers unable to maintain their integrity for a longer period when compared to HPMC K15. Therefore, HPMC 
K15 showed a better retardant effect when compared to the other three polymers over a period of $12 \mathrm{~h}$. Among three different concentrations of HPMC K15, the formulation with $50 \%$ polymer (SRL6) showed a good release profile over a period of $12 \mathrm{~h}$. This may be due to the increase in the concentration of polymer that may increase the thickness of the gel barrier and tortuosity. With 30-35\% of drug release in $1 \mathrm{~h}, 60-65 \%$ release in $6 \mathrm{~h}$ and the remaining drug release after $12 \mathrm{~h}$, the release is proposed to follow release profile as per Robinson and Eriksen equation [29]. Therefore, SRL6 formulation was optimized and selected as a sustainedrelease layer in the preparation of GBFTs.

GBFTs were directly compacted using the optimized formulations (IRL3 and SRL6) by varying the concentration of sodium bicarbonate (Table 3) to optimize the FLT and TFT. The developed tablets were characterized for post-compression parameters, drug release profile, and in-vitro floating ability.

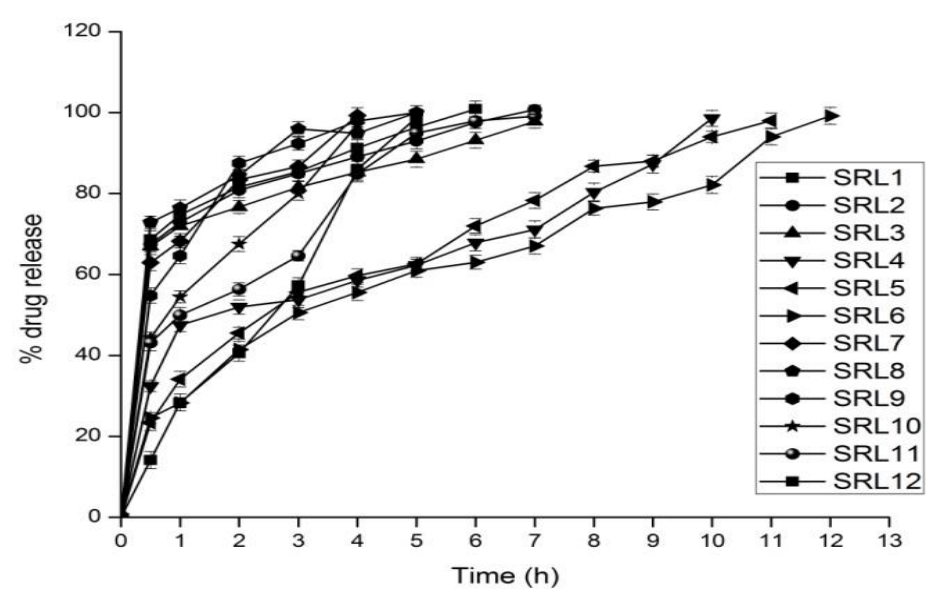

Figure 6. In-vitro release profile of sustained-release layer tablets.

\subsection{Post compression Parameters.}

Post compression parameters of the prepared GBFTs are shown in Table 4.

\subsection{General appearance.}

The general appearance of prepared bilayer tablets was elegant. As shown in Figure 7, pink color was added to distinguish the immediate-release layer from the sustained-release layer (white color).

\subsection{Weight variation.}

A weight variation test was performed to check whether uniform weight was maintained among all the formulation batches. It is affected by the flow properties of the powder blend. As the weight of the prepared tablet was $500 \mathrm{mg}$, the percentage deviation allowed was $5 \%(25 \mathrm{mg})$ as per IP. The prepared GBFTs were in the range of 498-500 mg (Table 4). So, these results suggested that weight variation was within the range, and there was no significant variation in weight between different batches of tablets. This showed uniform die filling during tablet compression. 
Figure 7. The general appearance of GBFTs with a pink immediate-release layer (front view) and white sustained-release layer (back view).

Table 4. Post-compression parameters of the prepared gastro-bilayer floating tablets.

\begin{tabular}{|c|c|c|c|c|c|c|c|}
\hline \multirow[t]{2}{*}{$\begin{array}{l}\text { Formulation } \\
\text { code }\end{array}$} & \multirow[t]{2}{*}{$\begin{array}{l}\text { Weight variation } \\
\text { (mg) }\end{array}$} & \multirow[t]{2}{*}{ Hardness $^{b}$} & \multirow[t]{2}{*}{ Friability $^{c}$} & \multicolumn{2}{|c|}{$\begin{array}{c}\text { Drug } \\
\text { content }(\%)^{\mathrm{d}}\end{array}$} & \multirow[t]{2}{*}{$\begin{array}{c}\text { FLT } \\
(\min )^{\mathrm{e}}\end{array}$} & \multirow[t]{2}{*}{$\begin{array}{r}\text { TFT } \\
(\mathbf{h})^{\mathbf{f}}\end{array}$} \\
\hline & & & & Nateglinide & Atenolol & & \\
\hline BLT1 & $498 \pm 1.17$ & $5.6 \pm 0.17$ & 0.638 & $99.85 \pm 1.18$ & $99.56 \pm 1.23$ & 8 & 8 \\
\hline BLT2 & $500 \pm 1.24$ & $5.5 \pm 0.19$ & 0.459 & $100.12 \pm 0.99$ & $100.08 \pm 1.24$ & 5 & 12 \\
\hline BLT3 & $499.9 \pm 1.11$ & $5.4 \pm 0.22$ & 0.329 & $99 \pm 0.20$ & $100.21 \pm 0.95$ & 2 & 12 \\
\hline
\end{tabular}

(a) Avg $\pm \%$ deviation, $\mathrm{n}=20$; (b) mean \pm S.D $\mathrm{n}=5$; (c) mean $\pm \mathrm{SD}, \mathrm{n}=3$ (6.5 g of tablet); (d) mean $\pm \mathrm{SD}, \mathrm{n}=10$; (e) mean $\pm \mathrm{SD}, \mathrm{n}=3$; (f) mean $\pm \mathrm{SD}, \mathrm{n}=3$.

Table 5. Kinetics of release from formulated tablets.

\begin{tabular}{l|c|c|c|c|c|c|c|c|c|c}
\multirow{2}{*}{$\begin{array}{l}\text { Formulation } \\
\text { code }\end{array}$} & \multicolumn{2}{|c|}{ Zero-order } & \multicolumn{2}{c}{ First-order } & \multicolumn{2}{c|}{ Higuchi } & \multicolumn{2}{c}{$\begin{array}{l}\text { Koresmeyer } \\
\text { and Peppas }\end{array}$} & \multicolumn{2}{c}{ Hixon Crowell } \\
\cline { 2 - 12 } & $\mathrm{r}^{2}$ & $\mathrm{~K}_{0}$ & $\mathrm{r}^{2}$ & $\mathrm{~K}_{1}$ & $\mathrm{r}^{2}$ & $\mathrm{~K}_{\mathrm{H}}$ & $\mathrm{r}^{2}$ & $\mathrm{n}$ & $\mathrm{r}^{2}$ & $\mathrm{~K}$ \\
\hline BLT1 & 0.886 & 6.563 & 0.884 & 0.110 & 0.977 & 25.63 & 0.971 & 0.372 & 0.926 & -0.220 \\
\hline BLT2 & 0.856 & 7.274 & 0.873 & 0.106 & 0.948 & 28.47 & 0.675 & 1.07 & 0.933 & -0.277 \\
\hline BLT3 & 0.886 & 6.402 & 0.701 & 0.121 & 0.969 & 24.9 & 0.971 & 0.378 & 0.834 & -0.223
\end{tabular}

\subsection{Hardness.}

Hardness gives an idea regarding how far the tablets resist capping, aberration, or breakage under conditions of handling and transportation. It affects drug dissolution and releases to some extent. The hardness of GBFTs was within the range of $5.4-5.6 \mathrm{~kg} / \mathrm{cm}^{2}$ (Table 4). Therefore, all formulations were within the range. Therefore, all the batches were found to have a good thickness and had the ability to withstand the handling abrasion.

\subsection{Friability.}

The ability of the tablet formulation to withstand mechanical stress is evaluated by friability testing. Friability of GBFTs was in the range of 0.325-0.638 (Table 4), i.e., below 1\% of the tablet. This indicates the developed tablets can withstand the mechanical shocks during handling and are suitable for further processing.

\subsection{Drug content.}

Assay of drug content uniformity is essential to assess the consistency of dosage forms. A verified UV-Visible Spectrophotometric method was used for the simultaneous estimation of the nateglinide and atenolol content. Drug content for all the prepared formulation batches was found in the range of 99.85- 100.12\% for nateglinide and 99.56-100.21\% for atenolol (Table 4). This was acceptable as per IP.

\subsection{In vitro floating ability.}

Ideally, a low FLT and high TLT is desirable for the continuous floating of the dosage form in the upper GIT to prevent escaping to the lower GIT. The optimum concentration of 
sodium bicarbonate is a critical factor in achieving the shortest lag time and highest TLT. This is because sodium bicarbonate evolves $\mathrm{CO}_{2}$ bubbles that react with $\mathrm{HCl}$ to form pores in the swollen polymer matrices of HPMC due to entrapment of bubbles. This helps the floating ability of the formulation. Thus optimum buoyancy was achieved by optimization of combinations of sodium bicarbonate and HPMC. In-vitro floating ability was determined by considering the sodium bicarbonate in three different concentrations $2.5 \%, 5 \%, 10 \% \mathrm{w} / \mathrm{w}$. An increase in concentration decreased the FLT from $25 \mathrm{~min}$ to $2 \mathrm{~min}$. The stages of the floating of the optimized formulation are shown in Figure 8. Formulation (BLT1 and BLT2) containing $2.5 \%$ and $5 \% \mathrm{w} / \mathrm{w}$ of sodium carbonate took more time to appear on the surface of the dissolution medium and floated up to $12 \mathrm{~h}$. The formulation containing $10 \% \mathrm{w} / \mathrm{w}$ sodium bicarbonate showed FLT of $2 \mathrm{~min}$ and TFT up to $12 \mathrm{~h}$. So, the formulation (BLT3) was considered as the optimized formulation as it has good FLT (2 min) along with TFT (up to 12 h).

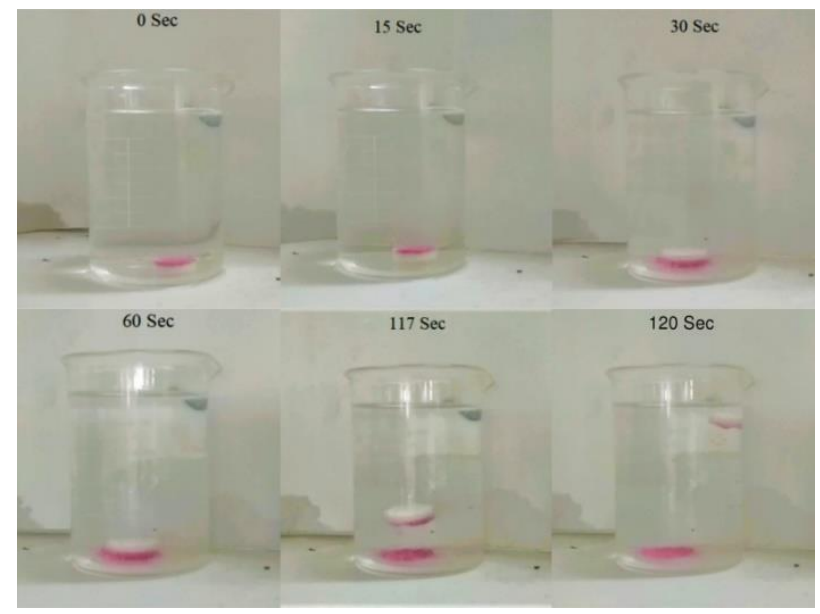

Figure 8. Stages of floating of prepared GBFT (BLT3).

\subsection{In-vitro dissolution studies.}

The nateglinide and atenolol release profiles of the GBFTs are depicted in Figure 9. Increasing concentrations of sodium bicarbonate may produce a higher level of effervescence that may result in an increased rate of pore generation. This ultimately results in rapid hydration of the matrices, and consequently, faster drug release may occur. The formulation BLT1 showed approximately $98 \%$ of atenolol and nateglinide over a period of $12 \mathrm{~h}$ and $60 \mathrm{~min}$, respectively (Figure 9).
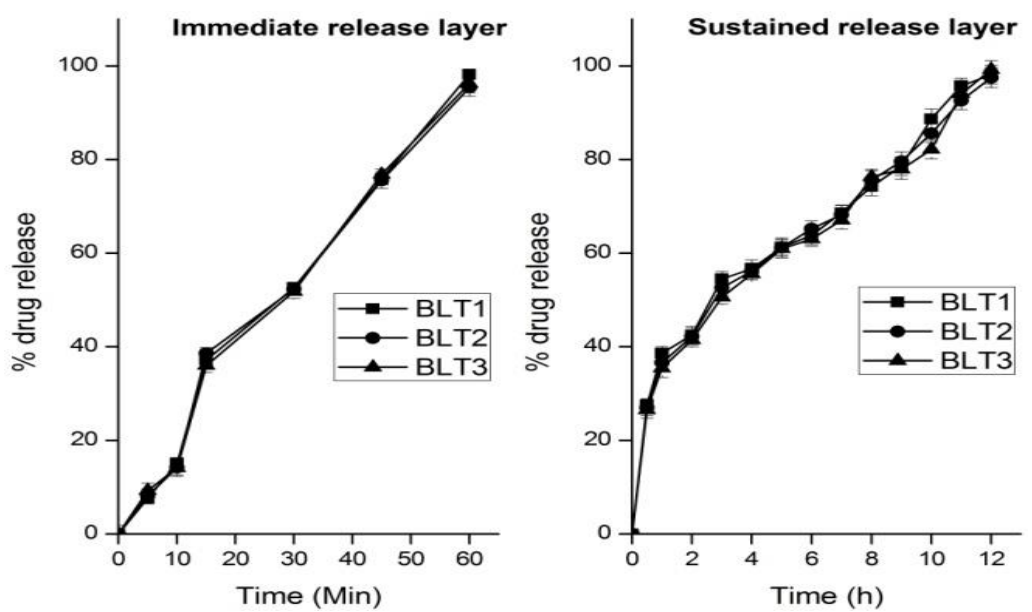

Figure 9. In-vitro release profile of nateglinide and atenolol from layers of the GBFTs. 
This may be due to a decreased rate of pore generation, which results in a slower rate of drug release. The BLT2 showed $97.5 \%$ atenolol and $95.4 \%$ of nateglinide release with 12 $\mathrm{h}$ and $60 \mathrm{~min}$, respectively. The formulation BLT3 showed a $100 \%$ drug release over a period of $12 \mathrm{~h}$ (Figure 9) without losing the integrity of the tablet. The immediate-release layer containing nateglinide released $100 \%$ within 60 min of dissolution. Therefore, BLT3 was selected as an optimized formulation.

\subsection{Kinetics of drug release.}

Optimized formulation showed a biphasic release pattern, i.e., the burst effect is followed by sustained-release. Burst effect may be due to a combination of factors, including the hydrophilic nature of drug, polymer, and method of preparation. The direct compression method allows the drug to be on the surface of the tablet. Therefore, when the tablet comes in contact with the dissolution medium, the drug present on the surface of the tablet immediately enters into the medium. Subsequently, drugs are released from the matrix. So, the burst effect is considered as the additive effect of the free drug present at the surface and the initial release of drug from the instantly swelled gel barrier. The presence of sodium bicarbonate may also facilitate drug release through the formation of bubbles and pores in the matrix.

Following analysis in zero and first-order model, a higher $\mathrm{r}^{2}$ value was obtained for zero-order compared (0.886) to first-order (0.701) (Table 5). This suggested that the formulation followed the zero-order release. The optimized formulation was studied for Higuchi and Hixon Crowell models, where Higuchi model $r^{2}$ value (0.969) was found to be higher than the Hixon Crowell value (0.834) (Table 5), which indicated that the release might follow diffusion mechanism. This may be due to the hydrophilic nature of drugs incorporated in a semisolid matrix or sodium bicarbonate that forms gas bubbles on reaction with the dissolution medium, which creates a porous system that allows the drug diffuses through the tortuous pathway created by the porous system.

\section{Conclusions}

The solubility of nateglinide was enhanced successfully using cremophor RH 40 by the solvent evaporation method. GBFTs were successfully developed using these optimized immediate and sustained-release layer. The gastro retention of the formulations was demonstrated with low FLT and $12 \mathrm{~h}$ TFT. This may result in higher bioavailability. However, this needs to be validated by a pharmacokinetic study. Further, pharmacodynamics may be studied to justify its application to manage the co-existing disease conditions of hypertension and diabetes.

\section{Funding}

This research received no external funding.

\section{Acknowledgments}

The authors would like to acknowledge Aurobindo Pharma Ltd., Hyderabad, India, for supplying the pure drug nateglinide. The authors are grateful to the management of Maharajah's College of Pharmacy, Andhra Pradesh, India, for providing all the necessary facilities to carry out this study. 


\section{Conflicts of Interest}

\section{The authors declare no conflict of interest.}

\section{References}

1. Homayun, B.; Lin, X.; Choi, H.-J. Challenges and Recent Progress in Oral Drug Delivery Systems for Biopharmaceuticals. Pharmaceutics 2019, 11, https://doi.org/10.3390/pharmaceutics11030129.

2. Tiwari, G.; Tiwati, R.; Sriwastawa, B.; Bhati, L.; Pandey, S.; Bannerjee, S.K. Drug delivery systems: An updated review. Int J Pharm Investig 2012, 2, 2-11, https://dx.doi.org/10.4103\%2F2230-973X.96920.

3. Lalge, R.; Thipsay, P.; Shankar, V.K.; Maurya, A.; Pimparade, M.; Bandari, S.; Zhang, F.; Murthy, S.N.; Repka, M.A. Preparation and evaluation of cefuroxime axetil gastro-retentive floating drug delivery system via hot melt extrusion technology. International Journal of Pharmaceutics 2019, 566, 520-531, doi:https://doi.org/10.1016/j.ijpharm.2019.06.021.

4. Simons, F.J.; Wagner, K.G. Modeling, design and manufacture of innovative floating gastroretentive drug delivery systems based on hot-melt extruded tubes. European Journal of Pharmaceutics and Biopharmaceutics 2019, 137, 196-208, https://doi.org/10.1016/j.ejpb.2019.02.022.

5. Guguloth, M.; Bomma, R.; Veerabrahma, K. Development of Sustained Release Floating Drug Delivery System for Norfloxacin: In Vitro and In Vivo Evaluation. PDA Journal of Pharmaceutical Science and Technology 2011, 65, 198-206, https://doi.org/10.5731/pdajpst.2011.00685.

6. Swain, R.; Nagamani, A.; Shankar, P. Formulation and Evaluation of Gastro-Bilayer Floating Tablets of Ezetimibe as Immediate Release Layer and Atenolol as Sustained Release Layer. Indian Journal of Pharmaceutical Education and Research 2019, 53, s93-s103, https://doi.org/10.5530/ijper.53.2s.53.

7. Rao, S.V.; Priyanka, B.; Padmalatha, K. Bilayer tablet technology: A novel approach. GSC Biol Pharm Sci 2019, 07, 022-028, https://doi.org/10.30574/gscbps.2019.7.2.0033.

8. Saeedi, P.; Petersohn, I.; Salpea, P.; Malanda, B.; Karuranga, S.; Unwin, N.; Colagiuri, S.; Guariguata, L.; Motala, A.A.; Ogurtsova, K.; Shaw, J.E.; Bright, D.; Williams, R. Global and regional diabetes prevalence estimates for 2019 and projections for 2030 and 2045: Results from the International Diabetes Federation Diabetes Atlas, 9th edition. Diabetes Research and Clinical Practice 2019, 157, https://doi.org/10.1016/j.diabres.2019.107843.

9. The official website for International Diabetes Foundation, Ninth edition, 2019, https://diabetesatlas.org/en/sections/worldwide-toll-of-diabetes.html (Accessed on $9^{\text {th }}$ March, 2020).

10. The atlas of heart disease and stroke. World Health Organization, 2019, https://www.who.int/newsroom/fact-sheets/detail/hypertension (Accessed on $10^{\text {th }}$ March, 2020).

11. Zhao, H.; Zeng, F.; Wang, X.; Wang, L. Prevalence, risk factors, and prognostic significance of masked hypertension in diabetic patients. Medicine 2017, 96.

12. Viswanathan, V.; Smina, T.P. Blood pressure control in diabetes - the Indian perspective. Journal of Human Hypertension 2019, 33, 588-593, https://doi.org/10.1038/s41371-019-0212-0.

13. Bassi, D.; Cabiddu, R.; Mendes, R.G.; Tossini, N.; Arakelian, V.M.; Caruso, F.C.R.; Bonjorno Júnior, J.C.; Arena, R.; Borghi-Silva, A. Effects of Coexistence Hypertension and Type II Diabetes on Heart Rate Variability and Cardiorespiratory Fitness Arquivos Brasileiros de Cardiologia 2018, 111, 64-72, https://doi.org/10.5935/abc.20180105.

14. Sharma, S.K.; Ruggenenti, P.; Remuzzi, G. Managing hypertension in diabetic patients--focus on trandolapril/verapamil combination. Vasc Health Risk Manag 2007, 3, 453-465.

15. Guerrero-García, C.; Rubio-Guerra, A.F. Combination therapy in the treatment of hypertension. Drugs Context 2018, 7, 212531-212531, https://dx.doi.org/10.7573\%2Fdic. 212531.

16. Tentolouris, N.; Voulgari, C.; Katsilambros, N. A review of nateglinide in the management of patients with type 2 diabetes. Vasc Health Risk Manag 2007, 3, 797-807.

17. Wright, J.M.; Musini, V.M.; Gill, R. First-line drugs for hypertension. Cochrane database syst Rev 2018, 4, https://doi.org/10.1002/14651858.CD001841.pub2.

18. Pawar, H.; Gharat, P.; Dhavale, R.; Joshi, P.; Rakshit, P. Development and Evaluation of Gastroretentive Floating Tablets of an Antihypertensive Drug Using Hydrogenated Cottonseed Oil. ISRN pharmaceutics 2013, 2013, 1-9, https://doi.org/10.1155/2013/137238.

19. He, W.; Li, Y.; Zhang, R.; Wu, Z.; Yin, L. Gastro-floating bilayer tablets for the sustained release of metformin and immediate release of pioglitazone: Preparation and in vitro/in vivo evaluation. International Journal of Pharmaceutics 2014, 476, 223-231, https://doi.org/10.1016/j.ijpharm.2014.09.056.

20. Swain, R.P; Pendela, S; Panda, S. Formulation and evaluation of gastro-bilayer floating tablets of simvastatin as immediate release layer and atenolol as sustained release layer. Indian J Pharm Sci 2016, 78, 458-468, https://doi.org/10.4172/pharmaceutical-sciences.1000140.

21. Swain, R.P; Subudhi, B.B. Effect of semicrystalline polymers on self-emulsifying solid dispersions of nateglinide: in vitro and in vivo evaluation. Drug Dev Ind Pharm 2018, 44, 56-65, https://doi.org/10.1080/03639045.2017.1371739. 
22. Jiménez-Castellanos, M.R.; Zia, H.; Rhodes, C.T. Design and testing in vitro of a bioadhesive and floating drug delivery system for oral application. International Journal of Pharmaceutics 1994, 105, 65-70, https://doi.org/10.1016/0378-5173(94)90236-4.

23. Higuchi, T. Kinetic analysis of in vitro release rates of zidovudine matrix tablets. Theoretical analysis of rate release of solid drugs dispersed in solid matrices. J Pharm Sci 1963, 52, 1145-9.

24. Korsemeyer, R.W.; Gurny, R.; Doelke, E.; Buri, P.; Peppas, N.A. Kinetic analysis of in vitro release of zidovudine matrix tablets. Mechanism of solute release from porous hydrophilic polymers. Int J Pharm Sci 1983, 4, 25-35.

25. Maggi, L.; Bruni, G.; Maietta, M.; Canobbio, A.; Cardini, A.; Conte, U. I. Technological approaches to improve the dissolution behavior of nateglinide, a lipophilic insoluble drug: Nanoparticles and co-mixing. International Journal of Pharmaceutics 2013, 454, 562-567, https://doi.org/10.1016/j.ijpharm.2013.06.084.

26. Pani, N.R.; Nath, L.K.; Acharya, S.; Bhuniya, B. Application of DSC, IST, and FTIR study in the compatibility testing of nateglinide with different pharmaceutical excipients. Journal of Thermal Analysis and Calorimetry 2012, 108, 219-226, https://doi.org/10.1007/s10973-011-1299-x.

27. Bruni, G.; Berbenni, V.; Milanese, C.; Girella, A.; Cardini, A.; Lanfranconi, S.; Marini, A. Determination of the nateglinide polymorphic purity through DSC. Journal of Pharmaceutical and Biomedical Analysis 2011, 54, 1196-1199, https://doi.org/10.1016/j.jpba.2010.12.003.

28. Tang, L.; Khan, S.U.; Muhammad, N.A. Evaluation and Selection of Bio-relevant Dissolution Media for a Poorly Water-Soluble New Chemical Entity. Pharmaceutical Development and Technology 2001, 6, 531540, https://doi.org/10.1081/pdt-120000291.

29. Eriksen, S.P.; Robinson, J.R. Theoretical Formulation of Sustained-Release Dosage Forms. Journal of Pharmaceutical Sciences 1966, 55, 1254-1263, https://doi.org/10.1002/jps.2600551118. 


\section{Supplementary data}

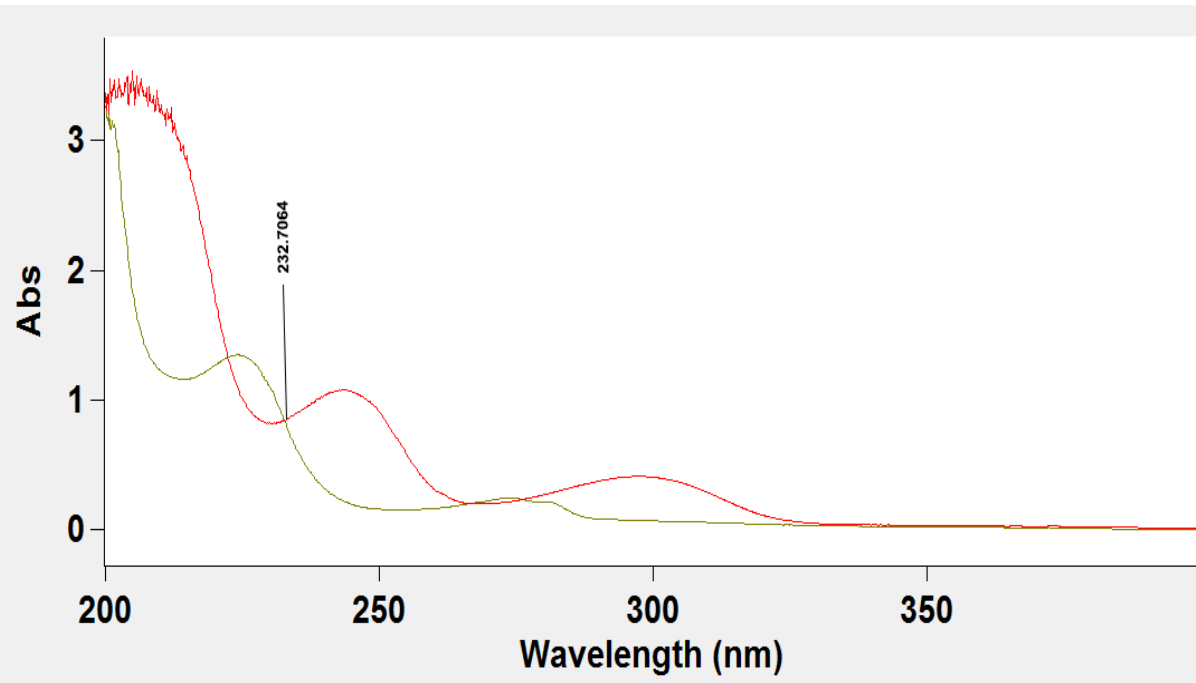

Figure S1. Simultaneous estimation of nateglinide and atenolol by U.V.-Visible Spectrophotometer.

\section{Linearity}

Table S1. Statistical Parameters of linearity.

\begin{tabular}{c|c|c}
\multirow{2}{*}{ Statistical Parameters } & \multicolumn{2}{|c}{ UV } \\
\cline { 2 - 3 } & \multicolumn{2}{|c}{ First Order } \\
\cline { 2 - 3 } & Nateglinide & Atenolol \\
\hline Linearity $(\mu \mathrm{g} / \mathrm{ml})$ & $5-25$ & $5-25$ \\
\hline Correlation coefficient $\left(\mathrm{R}^{2}\right)$ & 0.999 & 0.998 \\
\hline Regression Equation $\mathrm{y}=\mathrm{mx}+\mathrm{c}$ & $\mathrm{y}=0.023 \mathrm{x}+0.013$ & $\mathrm{y}=0.033 \mathrm{x}+0.024$ \\
\hline Slope $(\mathrm{m})$ & 0.023 & 0.033 \\
\hline Intercept $(\mathrm{c})$ & 0.013 & 0.024
\end{tabular}

Table S2. Concentration and absorbance values obtained for linearity curve determination.

\begin{tabular}{c|c|c|c|c}
\multirow{2}{*}{ S. no } & \multicolumn{2}{|c|}{ Nateglinide } & \multicolumn{2}{c}{ Atenolol } \\
\cline { 2 - 5 } & $\begin{array}{c}\text { Concentration } \\
(\boldsymbol{\mu g} / \mathbf{m l})\end{array}$ & $\begin{array}{c}\text { Absorbance at } \\
\mathbf{2 4 5} \mathbf{~ n m}\end{array}$ & $\begin{array}{c}\text { Concentration } \\
(\boldsymbol{\mu g} / \mathbf{m l})\end{array}$ & $\begin{array}{c}\text { Absorbance at } \\
\mathbf{2 2 5} \mathbf{~ n m}\end{array}$ \\
\hline 1 & 5 & 0.1309 & 5 & 0.1992 \\
\hline 2 & 10 & 0.2489 & 10 & 0.3525 \\
\hline 3 & 15 & 0.3597 & 15 & 0.5103 \\
\hline 4 & 20 & 0.4762 & 20 & 0.684 \\
\hline 5 & 25 & 0.5992 & 25 & 0.8622
\end{tabular}

\section{Accuracy}

\begin{tabular}{|c|c|c|c|c|c|}
\hline \multicolumn{6}{|c|}{ Table S3. Accuracy table of nateglinide. } \\
\hline S. no & $\begin{array}{c}\text { Level of addition } \\
(\%)\end{array}$ & $\underset{(\mu \mathrm{g})}{\text { Amount added }}$ & $\begin{array}{l}\text { Amount } \\
\text { found }(\mu \mathrm{g})\end{array}$ & \% Recovery & Average \\
\hline \multirow[t]{3}{*}{1} & \multirow[t]{3}{*}{50} & 10 & 9.56 & 95.6 & \multirow[t]{3}{*}{$97.1 \pm 1.26$} \\
\hline & & 10 & 9.87 & 98.7 & \\
\hline & & 10 & 9.70 & 97.0 & \\
\hline \multirow[t]{3}{*}{2} & \multirow[t]{3}{*}{100} & 20 & 19.55 & 97.7 & \multirow{3}{*}{$\begin{array}{l}98.53 \\
\pm 063\end{array}$} \\
\hline & & 20 & 19.88 & 99.4 & \\
\hline & & 20 & 19.70 & 98.5 & \\
\hline \multirow[t]{3}{*}{3} & \multirow[t]{3}{*}{150} & 30 & 29.88 & 99.6 & \multirow[t]{3}{*}{$98.96 \pm 0.57$} \\
\hline & & 30 & 29.75 & 99.1 & \\
\hline & & 30 & 29.46 & 98.2 & \\
\hline
\end{tabular}




\begin{tabular}{|c|c|c|c|c|c|}
\hline \multirow[b]{2}{*}{ S. no } & \multicolumn{5}{|c|}{ Table S4. Accuracy table of atenolol. } \\
\hline & $\begin{array}{c}\text { Level of addition } \\
(\%)\end{array}$ & $\underset{(\mu \mathrm{g})}{\text { Amount added }}$ & $\begin{array}{c}\text { Amount } \\
\text { found }(\mu \mathrm{g})\end{array}$ & \% Recovery & Average \\
\hline \multirow[t]{3}{*}{1} & \multirow[t]{3}{*}{50} & 10 & 9.46 & 94.6 & \multirow[t]{3}{*}{$95.76 \pm 1.37$} \\
\hline & & 10 & 9.77 & 97.7 & \\
\hline & & 10 & 9.50 & 95.0 & \\
\hline \multirow[t]{3}{*}{2} & \multirow[t]{3}{*}{100} & 20 & 19.05 & 95.25 & \multirow{3}{*}{$\begin{array}{l}95.33 \\
\pm 0.06\end{array}$} \\
\hline & & 20 & 19.08 & 95.4 & \\
\hline & & 20 & 19.07 & 95.35 & \\
\hline \multirow[t]{3}{*}{3} & \multirow[t]{3}{*}{150} & 30 & 29.15 & 97.16 & \multirow[t]{3}{*}{$97.76 \pm 0.69$} \\
\hline & & 30 & 29.62 & 98.73 & \\
\hline & & 30 & 29.22 & 97.4 & \\
\hline
\end{tabular}

\section{Precision}

\begin{tabular}{|c|c|c|c|}
\hline \multirow[t]{2}{*}{ S. no. } & \multirow[t]{2}{*}{$\begin{array}{c}\text { Concentration } \\
(\mu \mathrm{g} / \mathrm{ml})\end{array}$} & \multicolumn{2}{|c|}{$\begin{array}{c}\text { Nateglinide } \\
\text { Absorbance at } 245 \mathrm{~nm}\end{array}$} \\
\hline & & Intra- Day & Inter-Day \\
\hline 1 & 20 & 0.6820 & 0.6832 \\
\hline 2 & 20 & 0.6799 & 0.6795 \\
\hline 3 & 20 & 0.6834 & 0.6809 \\
\hline 4 & 20 & 0.6825 & 0.6854 \\
\hline 5 & 20 & 0.6856 & 0.6845 \\
\hline \multicolumn{2}{|c|}{ Average } & $0.6826 \pm 0.02$ & $0.68 \pm 0.024$ \\
\hline
\end{tabular}

Table S6. Precision table of atenolol.

\begin{tabular}{c|c|c|c}
\multirow{2}{*}{ S. no } & $\begin{array}{c}\text { Concentration } \\
(\boldsymbol{\mu} \mathbf{g} / \mathbf{m l})\end{array}$ & \multicolumn{2}{|c}{$\begin{array}{c}\text { Atenolol } \\
\text { Absorbance at225 nm }\end{array}$} \\
\cline { 3 - 4 } & & Intra- Day & Inter-Day \\
\hline 1 & 20 & 0.4608 & 0.4611 \\
\hline 2 & 20 & 0.4633 & 0.4625 \\
\hline 3 & 20 & 0.4659 & 0.4658 \\
\hline 4 & 20 & 0.4622 & 0.4677 \\
\hline 5 & 20 & 0.4593 & 0.4628 \\
\hline \multicolumn{2}{|c|}{ Average } & $0.4623 \pm 0.02$ & $0.4693 \pm 0.02$
\end{tabular}

\section{Limit of Detection (LOD) and Limit of Quantification (LOQ)}

LOD and LOQ were calculated based on the standard deviation of the analytical response and the slope of the calibration curve. The LOD and LOQ were 0.015, 0.050, 0.025 and $0.075 \mu \mathrm{g} / \mathrm{mL}$ respectively for nateglinide and atenolol with acceptable precision and accuracy under the stated conditions. 